\title{
Sistema de Gestão Ambiental: um estudo de caso da implantação do controle operacional no Beneficiamento de areia em uma indústria de fundições
}

\author{
Environmental Management System: a case study of the operational control implementation \\ on processing of sand in a Foundries Industry
}

\author{
Antônio Marcos Figueiredo Soares' ${ }^{1}$, Marcele Elisa Fontana², Danielle Costa Morais ${ }^{3}$ \\ ' Mestrando, Departamento de Engenharia de Produção, Universidade Federal de Pernambuco, Recife, Brasil. \\ ${ }^{2}$ Professora adjunta, Núcleo de Tecnologia, Universidade Federal de Pernambuco, Caruaru, Brasil. \\ ${ }^{3}$ Professora adjunta, Departamento de Engenharia de Produção, Universidade Federal de Pernambuco, Recife, Brasil.
}

\begin{abstract}
Resumo
Atualmente, as indústrias apresentam necessidade em seguir alguma normativa ambiental, seja por necessidade mercadológica, requisitos da legislação ou por iniciativa própria. Mais do que o atendimento aos requisitos de alguma norma específica, a implantação de uma estrutura que vise uma gestão ambiental, baseada em procedimentos padronizados, pode levar as empresas a atenderem aos requisitos ambientais em vigência ou a obterem resultados operacionais favoráveis. Uma das bases para a gestão ambiental é o seu controle operacional, pois dele surgirão todas as ações e índices de monitoramento ambiental necessários à administração da rotina específica. Desta forma, este artigo apresenta um modelo de implantação de controle operacional para gestão ambiental em indústrias de fundição. Um estudo de caso foi aplicado em uma indústria de fundição com beneficiamento de areia, pois o fato de se utilizar areia em seu processo de produção eleva a responsabilidade ambiental, em virtude da especificidade de extração e manipulação do produto. Como resultado verificou-se a melhora na eficiência das atividades operacionais vinculadas, principalmente a um controle operacional mais rígido, além do aumento na preocupação ambiental.
\end{abstract}

Palavras-chave: Sistema de Gestão Ambienta. Controle operacional. Indústria de fundição.

\begin{abstract}
Currently, the industries need to follow some environmental standard. It is due the marketing needs, requisites of the law or by its own initiative. More than satisfying the requirements of any specific standard, the implementation of an environmental management policy, based on standardized procedures, can lead companies to be in accordance with the valid environmental requirements, or to obtain favorable operating results. One of the bases for environmental management is its operational control, because from it all the actions and environmental observations' values appear for the specific routine administration. Therefore, this paper presents a deployment operational control model of an environmental management in foundry industries. A case study was applied in a foundry industry with sand processing, because the fact of using sand in their production process raises environmental responsibility, due to the specific extraction and manipulation of the product. As a result it was found improvement in the efficiency of the operational activities; this is due, mainly, to tighter control operational, beyond the increase in environmental concern.
\end{abstract}

Keywords: Environmental Management System. Operational control. Foundry industry. 


\section{INTRODUÇÃO}

O desenvolvimento econômico acelerado das últimas décadas trouxe inúmeros benefícios à sociedade, como avanços tecnológicos e científicos, por exemplo. No entanto, todo esse avanço elevou os impactos ao meio ambiente, derivados das atividades econômicas produtivas e extrativistas, estas dependentes, principalmente, de recursos naturais limitados. Desta forma, com visão de longo prazo, hoje se questiona o quanto os benefícios superam os custos associados ao impacto ao ambiente e à escassez de alguns recursos naturais.

Desta forma, as demandas de clientes e da sociedade, relacionadas aos cuidados com o meio ambiente, são crescentes e têm feito com que as organizações industriais direcionem esforços para adequar seus processos no sentido de diminuir ou eliminar impactos ambientais negativos. Opções, como produção ou manufatura limpa, padrões e instruções operacionais e sistemas de controle, têm sido utilizadas como ferramentas para contemplar tais necessidades (Avila \& Paiva, 2006). Assim, a questão ambiental passou a receber maior relevância na administração das empresas, a ponto de serem criadas normas de caráter internacional que regulamentam requisitos, a fim de minimizar os impactos sofridos pelo ambiente. Neste sentido, a Gestão Ambiental (GA) pode ser entendida como um conjunto de medidas que, se aplicadas de forma correta, permitem reduzir os impactos ambientais causados por uma organização. Como tal, a gestão ambiental é a gestão eficiente do relacionamento da organização com o meio ambiente (Trierweiller et al., 2012).

Segundo Dias (2004), o Brasil é o único país da América Latina que possui uma política específica para Educação Ambiental. Neste sentido, a Constituição Federal Brasileira de 1988 (Brasil, 2005) declara que: "Art. 225: Todos têm direito ao meio ambiente ecologicamente equilibrado, bem de uso comum do povo e essencial à sadia qualidade de vida, impondo-se ao Poder Público e à coletividade o dever de defendê-lo e preservá-lo para presentes e futuras gerações". Neste sentido, o art. $3^{\circ}$ da Resolução Conama 237/97 trata que "todas as atividades e empreendimentos considerados, efetiva ou potencialmente, causadores de significativa degradação do meio ambiente, dependerão de estudo de impacto ambiental (EIA) e de respectivo relatório de impacto sobre o meio ambiente (Rima)" (Brasil, 2007). "No RIMA as informações devem ser traduzidas em linguagem acessível, ilustradas por mapas, cartas, quadros, gráficos e demais técnicas de comunicação visual, de modo que se possam entender as vantagens e desvantagens do projeto, bem como todas as consequências ambientais de sua implementação" (Conselho Nacional do Meio Ambiente - CONAMA, 1986).

De acordo com Thoumy \& Vachon (2012) o conceito de gestão ambiental no nível organizacional pode ser definida considerando-se a forma como os recursos (por exemplo, dinheiro e tempo) são implantados no esforço da gestão ambiental. No nível mais básico, esforços de gestão ambiental são categorizados como redução da poluição (garantindo que a poluição não atinge o ambiente natural) ou prevenção (redução de poluição na fonte).

Segundo Angell \& Klassen (1999), na literatura pode-se encontrar duas perspectivas dominantes na implantação da gestão ambiental: (1) a restrição externa e (2) as perspectivas de componentes. A primeira considera os requisitos de desempenho ambiental como uma restrição externamente imposta sobre o sistema operacional. Em contraste, a perspectiva componente reconhece as questões ambientais como fatores operacionais legítimos, com implicações para a estratégia de operações. Mais importante, a segunda perspectiva reconhece explicitamente o potencial das operações planejarem, influenciarem e alavancarem as questões ambientais, dando vantagens competitivas interna e externamente. Nesta perspectiva, questões operacionais, tais como o controle da poluição, a minimização de resíduos e redução de materiais, a reutilização e / ou reciclagem, formam uma porção distinta da estratégia de operações. Em outras palavras, os impactos ambientais são influenciados ou por decisões operacionais estruturais ou infraestruturais.

Neste sentido, uma tipologia mais refinada, utilizando a natureza dos investimentos / gastos em esforços ambientais, faz uma distinção entre os investimentos estruturais infraestruturais e categoriza investimento ambiental e os gastos em três grupos principais: (i) de controle de poluição, (ii) prevenção da poluição e (iii) sistemas de gestão. Embora tanto prevenção como controle de poluição implicam em mudanças estruturais nos processos de produção ou especificações do produto, a prevenção da poluição visa encontrar e eliminar ou reduzir as fontes de impacto ambiental, que podem estar relacionadas com perdas de processo evitáveis e ineficiências de energia e material; enquanto o controle de poluição são os investimentos estruturais feitos para lidar com processo de emissões de 
poluentes depois de terem sido gerados. O uso de controles de poluição não melhora o processo e não elimina a poluição, mas pode impedir a poluição de afetar o meio ambiente (Gavronski et al., 2008; Thoumy \& Vachon, 2012).

Embora as tecnologias de prevenção da poluição (mudanças estruturais) reduzem a poluição na fonte, sistemas de gestão (mudanças de infraestrutura) também podem ser propícios para a redução da poluição na fonte através, de mudanças de procedimento e / ou diferentes formas de condução das operações. Em geral, projetos estruturais são mais complexos e exigem mais habilidades e envolvimentos de vários departamentos da empresa; esta complexidade irá dificultar, em maior medida, o resultado financeiro de um projeto (Thoumy \& Vachon, 2012). Segundo Pombo \& Magrini (2008), sob a óptica mais holística, é sadio que uma organização, dita ambientalmente visionária, tenha sua própria política ambiental. Pode-se dizer que a política ambiental da empresa traduz o seu compromisso com o meio ambiente e ela se concretiza através do Sistema de Gestão Ambiental (SGA).

Um SGA é uma estrutura padronizada, utilizada pelas empresas, para, sistematicamente, gerenciar as atividades que afetam o meio ambiente, pela integração de procedimentos e processos, envolvendo treinamento, monitoramento e registros. Estas atividades englobam pessoas, instrumentos e ações com o propósito de coletar e processar dados que possibilitem informações ambientais para gerenciamento e tomada de decisão (Avila \& Paiva, 2006).

Para atender às exigências de um SGA, destacam-se as normas da série ISO 14000 (Associação Brasileira de Normas Técnicas - ABNT, 2004). Desde a introdução das normas ISO 14000, em 1996, muitas empresas ao redor do mundo estão adotando-a e exigindo que seus fornecedores movam-se em direção a adotar o mesmo conjunto de normas (Babakri et al., 2003). O mais importante das normas da série ISO 14000 é o padrão de especificação do SGA, a ISO 14001, que se tornou uma importante ferramenta para as empresas demonstrarem a sua "preocupação" com o meio ambiente. Esta norma internacional caracteriza os elementos essenciais de um SGA e fornece uma estrutura para as organizações que buscam reduzir seus impactos ambientais, além de regulamentar os requisitos (Delmas \&Toffel, 2008).

Um dos elementos-chave da norma ISO 14001 é a melhoria contínua do desempenho ambiental, definido como "um processo de reforço do SGA, a fim de atingir melhorias no desempenho ambiental global consistente com a política ambiental da organização" (International Organization for Standardisation - ISO, 2004). Entre os benefícios para a empresa certificada estão: satisfação de necessidades contratuais (principalmente para exportação); expansão de mercados e da base de clientes; maior competitividade; melhoria da imagem principalmente para clientes, fiscalização, funcionários, investidores e para as comunidades envolvidas com a empresa (Bispo \& Cazarini, 2006). Neste sentido, Avila \& Paiva (2006) destacam que as mudanças nas organizações, para atendimento dos requisitos da ISO 14001 durante a fase de implantação e adequação do SGA, têm maior impacto nos processos de produção, nos quais medidas são tomadas para alinhamentos legais e adaptações técnicas.

Diante disso, as indústrias de base são alvo de preocupação ambiental, haja vista os efeitos que essas causam ao meio ambiente, em função da grande dependência extrativista que possuem. Nesse grupo, estão enquadradas as indústrias de fundição, talvez uma das maiores representantes das indústrias de base no mercado internacional. Assim, a responsabilidade ambiental destas indústrias, que manipulam sucatas metálicas ou minérios afins e areia no seu processo, é elevada. Valle (2002) afirma que "os benefícios alcançados com a destinação correta dos resíduos gerados e a eliminação de eventuais multas e penalizações, causadas por uma má gestão ambiental, podem ser expressivos, mesmo no curto prazo".

Porém, o processo de implantação de sistemas certificáveis de gestão ambiental em indústrias, tal como o SGA, gera mudanças significativas na cultura e estrutura destas empresas e devem ser devidamente consideradas por gestores e consultores (Oliveira \& Pinheiro, 2010). Além disso, Anton et al. (2004) argumentam que a abrangência do SGA pode variar bastante de uma empresa para outra.

Dessa forma, com base em modelos apresentados e desenvolvidos para outros setores, o presente trabalho tem por objetivo propor um modelo para a implantação do Controle Operacional de um Sistema de Gestão Ambiental para a indústria de fundição. Espera-se, com isso, auxiliar na confecção do documento oficial, que conterá as informações necessárias para a prática da rotina de Controle Operacional sobre a demanda gerada pelos impactos ambientais em empresas de fundição e, assim, que estas possam regulamentar-se e habilitar-se à certificação de normas ambientais vigentes. Para verificar o comportamento do modelo, o mesmo foi aplicado em um estudo de caso de uma industria 
de fundição que possui extração e beneficiamento de areia próprio.

Além desta introdução, o artigo está organizado da seguinte maneira: a secção 2 define termos gerais relacionados ao assunto; a secção 3 apresenta o modelo para implantação do Controle Operacional de um Sistema de Gestão Ambiental em indústrias de fundição; em seguida é apresentado o estudo de caso na secção 4; os resultados do estudo de casos são relatados na secção 5; e, por fim, são feitas as considerações finais do artigo.

\section{SISTEMA DE GESTÃO AMBIENTAL (SGA)}

Um Sistema de Gestão Ambiental (SGA) é um instrumento bem estabelecido e fundamental na habilidade de uma empresa em reduzir seus impactos ambientais, enquanto simultaneamente melhorar o desempenho global (sua eficiência operacional). Em outras palavras, o SGA é investimento de infraestrutura feito em uma coleção de práticas e procedimentos operacionais de gestão ambiental que ajudam uma organização ou uma empresa à atingir os seus objetivos ambientais, destinados a reduzir a geração de resíduos; para evitar a geração de resíduos causados por acidentes; e com segurança e eficácia gerenciar quantidades não conformes de resíduos (Gavronski et al., 2008; Inoue, et al., 2013; Melnyk et al., 2003).

Um SGA consiste de uma estrutura de papéis e responsabilidades e um conjunto relacionado de procedimentos para a gestão e para políticas ambientais das organizações. Estes incluem aspectos diretos e indiretos ambientais (tais como o cumprimento dos requisitos legais e outros), programas de gestão ambiental (para garantir a melhoria contínua do meio ambiente, bem como a formação eficiente, conscientização e competência), além de documentação relevante, registros e de comunicação, controle operacional, procedimentos de emergência e de resposta, monitoramento e medição, ações de não conformidade, corretivas e preventivas, auditorias periódicas (Gasbarro et al., 2013).

O sistema com base na norma ISO 14001 é um dos modelos de gestão ambiental (GA) mais adotado em todo o mundo. Trata-se de uma referência certificável em forma de requisitos que exige uma série de procedimentos e iniciativas, sem determinar como devem ser executados, além de exigir que a legislação ambiental local seja cumprida (Oliveira \& Pinheiro, 2010). Os elementos-chave, ou os princípios definidores, de um SGA, baseados na NBR Série ISO 14001, através dos quais podem ser verificados os avanços de uma empresa em termos de sua relação com o meio ambiente, são: (1) Política ambiental; (2) Planejamento; (3) Implementação e operação; (4) Verificação e ação corretiva; (5) Análise crítica. Nicolella et al. (2004) descrevem estas etapas da seguinte maneira:

1) Política Ambiental: deve ser consubstanciada por meio de um documento escrito - carta de compromisso da empresa - que aborde todos os valores e filosofia da empresa, relativos ao meio ambiente, bem como aponte os requisitos necessários ao atendimento de sua política ambiental, por meio dos objetivos, metas e programas ambientais.

2) Planejamento: a Série ISO 14001 recomenda que a organização formule um plano para cumprir sua Política Ambiental. Este plano deve incluir os seguintes tópicos: aspectos ambientais; requisitos legais e outros requisitos; objetivos e metas; e programas de gestão ambiental.

3) Implementação e Operação: a empresa deve desenvolver os mecanismos de apoio necessários para atender o que está previsto em sua política, e nos seus objetivos e metas ambientais. Para tanto é previsto as seguintes itens básicos: (a) Estrutura organizacional e Responsabilidade; (b) Treinamento, Conscientização e Competência; (c) Comunicação; (d) Documentação do Sistema de Gestão Ambiental; (e) Controle de documentos; (f) Controle operacional; (g) Preparação e atendimento a emergências.

4) Verificação e Ação Corretiva: este item da norma cria condições de se averiguar se a empresa está operando de acordo com o programa de gestão ambiental previamente definido, identificando aspectos não desejáveis e mitigando quaisquer impactos negativos, além de tratar das medias preventivas. A Verificação e Ação Corretiva são etapas orientadas por quatro características básicas do processo de gestão ambiental: Monitoramento e Medição, Não conformidades e Ações Corretivas e Preventivas, Registros, e Auditoria do SGA.

5) Análise Crítica: após a etapa da auditoria, e considerando possíveis mudanças nos cenários internos e externos, como novas pressões de mercado e as recentes tendências do ambiente 
externo da empresa - além do compromisso de melhoria contínua requerido pela SGA -, é o momento da administração identificar a necessidade de possíveis alterações em sua Política Ambiental, nos seus objetivos e metas, ou em outros elementos do sistema. Em resumo, aqui o processo de gestão pode ser revisado, bem como o processo de melhoria contínua exercitado.

Para Oliveira \& Pinheiro (2010), o desenvolvimento e a implantação deste tipo de sistema, baseado na norma ISO 14001, têm enfrentado uma série de problemas que vão desde o baixo envolvimento da alta direção até a dificuldade de interpretação de procedimentos escritos, destacando-se aqueles relacionados aos recursos humanos: baixo nível de escolaridade e treinamento, desmotivação e resistência à mudança. Assim, eles proporão a gestão de pessoas como ferramenta para a sistematização da gestão ambiental ISO 14001 em empresas industriais. Eles apresentam sugestões de práticas relacionadas aos seguintes elementos: alta direção, gestão de pessoas, comitê de gestão ambiental, missão e políticas, treinamento e comunicação.

Contudo, a implantação do SGA é totalmente independente de uma futura certificação. As etapas necessárias para sua implantação são maiores que os da certificação, porém em todas essas etapas têm-se como meta aquela certificação. Essas etapas são: (a) o comprometimento e a colaboração de todos na empresa, desde a alta direção até os empregados mais simples; (b) fazer uma avaliação das práticas e dos procedimentos ambientais já existentes; (c) planejar a migração para o novo sistema; e (d) implementá-1o (Bispo \& Cazarini, 2006).

Neste sentido, o Controle Operacional pode ser visto como uma das bases para a implementação e manutenção de uma Gestão Ambiental. Babakri et al., (2003) destacam que o controle operacional está entre os elementos da ISO 14001 que requerem maior esforço para implantação. Sobre o controle operacional a norma disserta:

"A organização deve identificar e planejar as operações que estão associadas aos aspectos ambientais significativos identificados, consistentes com a sua política ambiental e os seus objetivos e metas, de forma a garantir que estas operações serão realizadas sob condições específicas: a) estabelecendo, implementando e mantendo um ou mais procedimentos documentados para controlar as situações onde a sua inexistência possa conduzir a desvios a política ambiental e aos objetivos e metas; b) definindo critérios operacionais no(s) procedimento(s); e c) estabelecendo, implementando e mantendo procedimentos relacionados com os aspectos ambientais significativos identificados dos bens e serviços utilizados pela organização, e comunicando os procedimentos e requisitos aplicáveis aos fornecedores, incluindo subcontratados" (ISO, 2004).

Nesta visão, um bom SGA irá permitir que a empresa descubra maneiras de reduzir seus impactos ambientais, reduzindo, simultaneamente, os custos e aumentando a produtividade. Além disso, o SGA irá coordenar as atividades ambientais da empresa para alcançar uma maior eficiência e eficácia organizacional (Bansal \& Bogner, 2002). Porém, segundo Nishitani et al. (2012), a implementação de uma SGA por si só é apenas um componente secundário de várias atividades destinadas a melhorar a produtividade implementada em resposta ao mercado. A preocupação ambiental e o cumprimento da legislação ambiental são motivados, pelo menos em parte, por uma unidade de vantagem competitiva (Wu, 2009).

Assim, o desempenho ambiental de uma empresa pode ser influenciado pela abrangência do SGA, bem como por outros fatores, tais como os níveis de produção, a pressão dos consumidores "verdes", os custos potenciais de conformidade e passivos sob normas ambientais obrigatórias, e as características específicas da empresa (Anton et al., 2004).

Na literatura é possível encontrar artigos que enfatizam as motivações para a introdução de um SGA (Johnstone \& Labonne, 2009) e a influência dos stakeholders na adoção de padrões que contribuem, tal como a ISO 14001 (Castka \& Prajogo, 2013; Nishitani, 2009); críticas às classificações das empresas em relação à implementação voluntária do SGA (Stevens et al., 2012); medidas de avaliação da implantação do SGA (Avila \& Paiva, 2006; Bispo \& Cazarini, 2006; Zhang et al., 2014) e do seu impacto sobre o desempenho empresarial e ambiental (Earnhart, 2013; Luz et al., 2006; Melnyk et al., 2003; Sellitto et al., 2010); avaliação da geração de resíduos e/ou do impacto ambiental (Nogueira \& Garcia, 2013; Seiffert, 2008) e uso de métodos de apoio à decisão multicritério para hierarquizar as alternativas minimizadoras ou mitigadoras dos problemas ambientais (Paoli \& Moraes, 2011); a 
influência da certificação ISO 14001 nos investimentos em inovação ambiental (Inoue et al., 2013) ou na rentabilidade das empresas (Lo et al., 2012).

No entanto, percebe-se, ainda, uma carência de trabalhos que apresentam o passo a passo da aplicação das etapas necessárias para a implantação de um SGA. Em muito, isso se deve ao fato do SGA ser implantado conforme as especificações de cada empresa. Anton et al. (2004) enfatizam que as empresas têm flexibilidade considerável na extensão em que adotam um SGA e, assim, a abrangência do SGA pode variar bastante entre as empresas.

Savely et al. (2007), por exemplo, apresentou um modelo de implementação do SGA para universidades norte-americanas. Seu modelo foi constituído por três fases: (I) é composta de ganhar apoio da alta gerência, definindo uma estrutura de prestação de contas, identificar os requisitos legais, as operações de revisão e identificação de atividades que podem afetar o meio ambiente e o desenvolvimento de uma política ambiental; (II) é definida como a criação de programas ambientais com objetivos e metas e monitoramento e medição de operações ambientais, estabelecendo um sistema de controle de documentos e documentação, criação e implementação de procedimentos ambientais necessários e treinamento e comunicação; (III) consiste em auditoria por partes internas e externas.

Contudo, verifica-se a necessidade de adaptar modelos como este à realidade das indústrias de base. Por este motivo, neste artigo será enfatizada a aplicação do SGA em um estudo de caso de uma indústria de fundição. Além disso, o modelo proposto enfatizará a fase de 'controle operacional' por acreditar ser a base para a implementação e manutenção de um SGA.

\section{I Gestão da qualidade e Sistema de Gestão Voluntário na Gestão ambiental}

Pombo \& Magrini (2008) apresentaram um panorama de aplicação da norma ISO 14001 no Brasil, em que observou que as empresas tendem a incorporar novos aspectos às certificações, integrando seus sistemas: ambiental, de qualidade e de saúde e segurança no trabalho. Em países em desenvolvimento com grandes desigualdades sociais, como o Brasil, vislumbra-se ainda uma tendência recente muito promissora, a responsabilidade social empresarial.

Zhu et al. (2013) demonstraram que, onde as pressões institucionais nacionais e internacionais levam ao sucesso da implementação de ISO 9000, esta fornece rotinas de aprendizagem associadas e mudanças culturais que motivam a organização na realização de investimentos em conhecimentos necessários para a ISO 14001. Em outras palavras, a ISSO 900 pode levar ao sucesso da implementação de sistemas de gestão ambiental.

Segundo Oliveira (2004 apud Bispo \& Cazarini, 2006), a série de normas ISO 14000 buscou o alinhamento com a série de normas sobre Qualidade, a série ISO 9000, deixando clara a necessidade de integração entre os conceitos de qualidade e de meio ambiente. A base para a elaboração de um Sistema de Gestão Ambiental é a mesma utilizada para a elaboração do Sistema de Gestão da Qualidade. Essa equivalência entre os modelos facilita o trabalho das organizações que tenham como objetivo melhorar a qualidade ambiental de seus processos. Segundo Brendler \& Brandli (2011), as próprias normas ISO apresentam um quadro de correspondência entre seus requisitos. O objetivo dessa comparação é demonstrar que ambos os sistemas podem ser utilizados conjuntamente por organizações que já estejam operando uma dessas normas e desejem integrar ambas.

Em resumo, a literatura fornece suporte à proposição de que as práticas de gestão ambiental têm um forte impacto sobre o desempenho operacional, se combinado com as práticas e programas de gestão de qualidade. Mais especificamente, empresas ganham benefícios de desempenho mais elevados em termos de custo, flexibilidade e desempenho de entrega, quando as práticas de gestão ambiental estão na presença de altos níveis de investimentos em práticas de gestão de qualidade (Wiengarten \& Pagell, 2012).

Assim, os Sistemas de Gestão Integrados (SGIs) são uma tendência crescente e irreversível, em que as semelhanças dos sistemas favorecem toda e qualquer abordagem de integração. Brendler \& Brandli (2011) estudaram a integração entre os sistemas de Gestão Ambiental (SGA) e de Gestão da Qualidade (SGQ) de uma organização, em um único sistema, como uma estratégia empresarial. Eles observaram que, normalmente, o SGA é implantando a partir do SGQ, isto porque é comum que as empresas tenham primeiramente seu sistema de gestão da qualidade. Segundo Wiengarten \& Pagell (2012), um SGQ que funcione bem pode ser visto como pré-requisito para um SGA de sucesso. Segundo Borella \& Naime (2012), um sistema integrado pode levar a empresa a ter vantagens competitivas, de forma a garantir sua sobrevivência para com o futuro. 
Neste sentido, Angell \& Klassen (1999) argumentam que há dois padrões de pensamento: (1) o primeiro propõe que ferramentas de qualidade devem ser aplicadas conforme o necessário nas questões ambientais com base no público, reguladores e exigências de clientes; (2) o segundo defende que as preocupações ambientais devem, necessariamente, conter uma definição ampliada de qualidade.

Contudo, o conceito de Gestão da Qualidade Total (Total Quality Management - TQM) pode ser considerado a força motriz por trás das mudanças que estão ocorrendo nas organizações de hoje. TQM é uma filosofia de gestão integrada e um conjunto de práticas que enfatizam a melhoria contínua, atendendo as exigências dos clientes, reduzindo o retrabalho, o pensamento de longo prazo, o aumento da participação dos trabalhadores e trabalho em equipe, o processo de redesign, benchmarking competitivo, a equipe baseada em resolução de problemas, a medição constante de resultados e relacionamentos mais estreitos com fornecedores (Pun, 2002).

A Manutenção Produtiva Total (Total Productive Maintanance - TPM) pode ser considerada como a fase inicial de uma estratégia global da TQM, porque envolve transferência de habilidade a todos os níveis organizacionais e entre muitas relações diferentes existentes dentro da organização. A TPM trata, especificamente, da combinação de operadores e mecânicos em um único time que identifica tarefas existentes que causam demoras, cria desperdício e reduz produtividade. Para a Implantação do TPM, tem-se: Apresentação e Treinamento; Manutenção Participativa; e LPP - Lição Ponto a Ponto e Instrução de Trabalho (Belinelli et al, 2009; Maggard, 1992).

Já um sistema de gestão ambiental fornece um conjunto de ferramentas capazes de estabelecer as alterações, através de mecanismos e técnicas encomendadas, e é essencial para melhorar o desempenho e auxiliar na identificação e gestão dos riscos e obrigações ambientais. Além disso, um sistema baseado na responsabilidade organizacional, controles de gerenciamento e análise de sistemas e planejamento, podem ter um maior grau de proatividade das partes envolvidas e pode ser um instrumento para compensar os custos da melhoria do desempenho ambiental, reduzindo o trade-off entre competitividade e conformidade legal (Gavronski et al., 2013).

A dependência cada vez maior da política ambiental, em incentivos baseados no mercado, tem levado as empresas a mudar, a partir de abordagens de gestão regulação orientadas para estratégias pró-ativas que envolvem a adoção voluntária de SGA (Anton et al., 2004). Neste sentido, as organizações, geralmente, têm duas opções de estratégia voluntária de gestão ambiental: (a) implementação de práticas individuais (por exemplo, o custo ambiental de contabilidade ou auditoria interna), ou (b) participação em programas formais de gestão ambiental voluntária (PEVs), tal como LEED (Liderança em Energia e Design Ambiental) de certificação construção verde.

Estudos indicam que pressões regulatórias estão entre os fatores mais importantes que influenciam positivamente a gestão ambiental voluntária. No entanto, a regulamentação é amplamente considerada mais cara e menos eficiente do que a ação voluntária. Neste sentido, antes das leis serem aprovadas, as organizações podem tentar antecipar ou influenciar futuras regulamentações e ganhar vantagem competitiva através da implementação voluntária de alta qualidade, que reduz a concorrência de preços e aumenta os lucros. Depois da aprovação das regulamentações, as organizações podem buscar alívio regulatório, tais como inspeções reduzidas, devido à postura voluntária à conformidade (Jones, 2010).

Embora a ISO 14001 tenha sido concebida como uma norma voluntária, algumas organizações podem ter a adotado devido à sensibilidade à pressão de seus clientes e/ou fornecedores. Além disso, organizações que percebem que um grande número dos seus concorrentes adotaram ISO 14001 são mais propensas a adotar o padrão (Delmas \& Toffel, 2008).

\section{MODELO DE IMPLANTAÇÃO DO CONTROLE OPERACIONAL DE UM SGA}

Com base nas informações levantadas na revisão da literatura, neste artigo pretende-se apresentar um modelo de implantação do SGA específico à indústria de fundição, enfatizando formulação e implantação do 'Controle Operacional'. Para tanto, o modelo apresentado levará em conta as fases de implantação do SGA apresentadas por Bispo \& Cazarini (2006), mas enfatizará a fase II do modelo de Savely et al. (2007), bem como os itens que compõem o $3^{\circ}$ princípio da NBR Série ISO 14001 (Implementação e Operação). descrita por Nicolella et al. (2004), onde se encontra o 'Controle Operacional'. O Controle Operacional se refere ao compromisso procedimental sobre o qual a empresa estabelece as instruções ou orientações. no sentido de se gerenciar os impactos causados pelos aspectos ambientais 
previamente identificados.

A objetividade encontrada em um conteúdo procedimental de um Controle Operacional faz com que a difusão do conceito educacional corporativo, acerca da temática ambiental, pareça mais prática e mais correlacionada com a operação (chão de fábrica) da empresa. Os colaboradores, principalmente aqueles que fazem parte da operação basal da fábrica, passam a visualizar a gestão ambiental como parte integrante da operação e não mais como algo que faz apenas, e tão somente, parte das funções gerenciais da empresa. Portanto, espera-se que o modelo proposto possa servir como catalisador de um conjunto de ações mais amplas, no tocante a administração das questões ambientais. Desta forma, o modelo é dividido em duas etapas principais:

1. Preparação: o intuito é criar um ambiente favorável à implantação do SGA e futura certificação, por intermédio de definições de responsabilidades, autoridades, prazos, etc.;

2. Confecção do documento de Controle Operacional: a principal tarefa é materializar as informações em um procedimento claro e objetivo, acessível a todos os envolvidos no processo.

Como aqui se está interessando em focar na importância do 'Controle Operacional' no processo de desenvolvimento de um SGA, a divisão do modelo nestas duas etapas visa, basicamente, enfatizar a importância deste documento, haja vista que emergirá dele toda a rotina de destinação dos resíduos gerados e, por conseguinte, da Gestão Ambiental.

\section{I Etapa I - Preparação}

O primeiro passo na implementação de um SGA deve ser a formalização, por parte da direção da empresa, perante a sua corporação, do desejo de a instituição adotar um SGA, deixando claro suas intenções e enfatizando os benefícios a serem obtidos com a sua adoção (Nicolella et al., 2004). A etapa de preparação pode ser dividida como mostra a figura 1 .

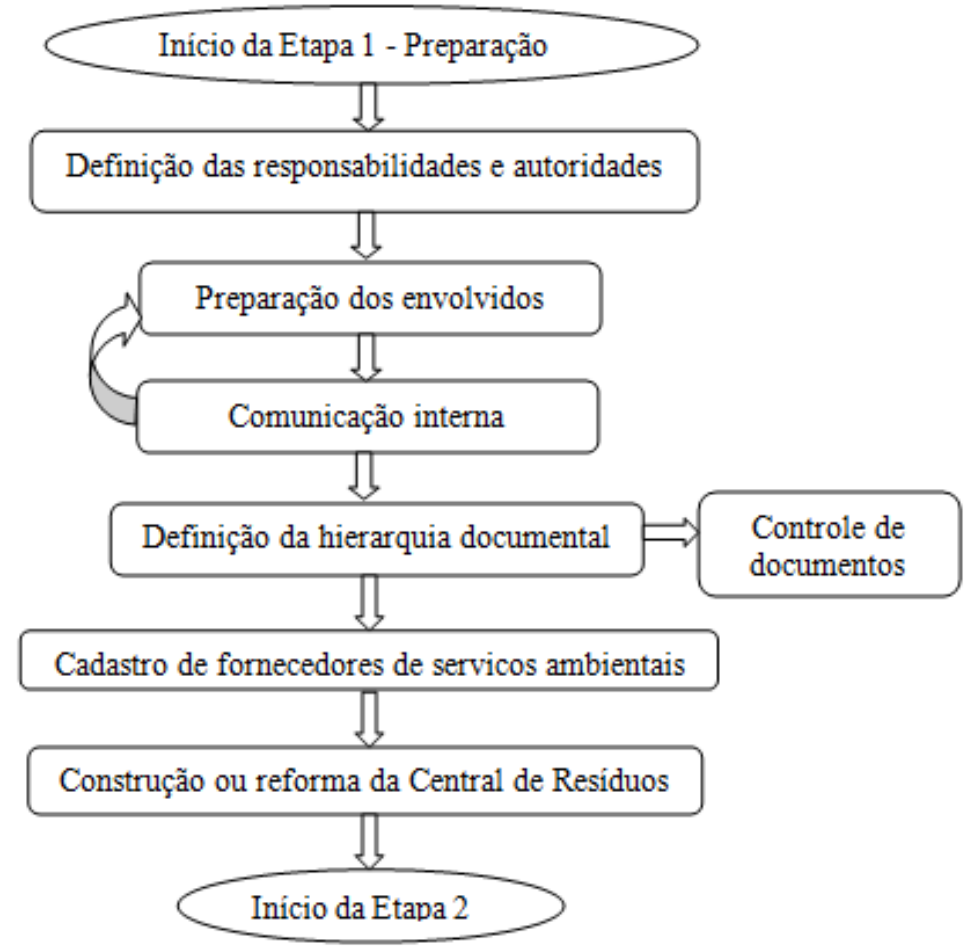

Figura 1. Fluxograma de implantação na fase de preparação

a) Definição das responsabilidades e autoridades

Cada empresa possui grupos funcionais com base nas suas necessidades administrativas e nas características do processo. No entanto, para fins de implantação de um sistema de Gestão Ambiental, podem-se considerar quatro divisões e suas respectivas responsabilidades: 
- Membros da direção: são os representantes ou procuradores dos acionistas; têm a função de aprovar a política ambiental, aprovar ou demandar correções para as análises feitas sobre o sistema e garantir gerenciar as questões relacionadas a aspectos legais.

- Membros da Gestão Gerencial: os profissionais responsáveis por esse grupo funcional, dentro de um Sistema de Gestão Ambiental, devem ser da área de qualidade ou de segurança. Eles têm como responsabilidades gerenciar as análises críticas do sistema, fornecer subsídios e recursos para implantar as ações, coordenar o cronograma de implementação do sistema, preparar as principais competências para a implementação do sistema, distribuir as responsabilidades para a elaboração de procedimentos próprios do sistema;

- Membros da Gestão Operacional: profissionais de média gerência ou responsáveis pela supervisão de equipes. Estes têm a responsabilidade de criar os procedimentos e registros do SGA, assim como treinar os operadores, principalmente, em relação ao controle operacional, já que este é um dos mais importantes documentos do SGA. Deve-se eleger um Padrinho do Sistema, dentre os supervisores, e este deve se reportar ao grupo funcional anterior para ele fazer uma análise crítica do sistema.

- Colaboradores da Operação: são as pessoas que trabalham no processo. Eles têm como responsabilidade o cumprimento dos itens estabelecidos no procedimento e no controle operacional.

Para a reunião de análise crítica do SGA, deve ser eleito um Comitê de Implementação da Manutenção. Dele devem fazer parte, no mínimo, um membro da direção, o gerente responsável pelo sistema, o padrinho do SGA e mais um membro da supervisão.

\section{b) Preparação dos envolvidos}

Treinar todos que os membros da organização, de acordo com as atividades que desempenham dentro da empresa, para colaborarem voluntariamente com o processo. Esta etapa pode ser realizada em paralelo com a 'comunicação interna', pois há influências mutuas.

\section{c) Comunicação interna}

Essa parte consiste em difundir a todos os colaboradores o conhecimento sobre o SGA a ser aplicado na empresa. "A comunicação interna é importante para assegurar a implementação eficaz do sistema de gestão ambiental" (ISO, 2004).

Segundo Oliveira \& Pinheiro (2010), os meios de comunicação interna, geralmente utilizados nas empresas, são os quadros de aviso disponibilizados em lugares estratégicos de grande movimentação de pessoas, boletim informativo, jornal, revista e e-mail. Em resumo, a comunicação interna durante o processo deve considerar:

$\checkmark$ Utilização de linguagem simples e objetiva, compatível com o nível de educação do público-alvo;

$\checkmark$ Identificação dos meios mais acessíveis para a divulgação externa das ações ambientais, com base nos recursos financeiros disponíveis;

$\checkmark$ Ter preocupação em não tornar o meio de comunicação banal e desinteressante.

\section{d) Definição da hierarquia documental}

A documentação pode ser compreendida como um meio de assegurar que o sistema de gestão ambiental seja compreendido não só pelo público interno, mas também pelo ambiente externo com o qual a empresa mantém relações, tais como clientes, fornecedores, governo, sociedade civil em geral, etc. A natureza da documentação pode variar em função do porte e da complexidade da empresa (Nicolella et al., 2004).

\section{e) Controle de documentos}

Os documentos exigidos pela Série ISO 14001 devem obedecer a procedimentos para o seu controle, de maneira que toda a documentação possa ser localizada, analisada e, periodicamente, atualizada quanto à conformidade com os regulamentos, leis e outros critérios ambientais assumidos pela empresa. Da mesma forma, exige que a empresa possua um controle dos documentos do sistema de gestão ambiental, requerendo, para isso, controle da distribuição da versão atualizada e da eliminação das versões desatualizadas (Nicolella et al., 2004). 


\section{f) Cadastro de fornecedores de serviços ambientais}

Os fornecedores de serviços como aterros industriais, aterros sanitários, incineradores, etc., devem ser recrutados para que o Comitê de Implantação possa avaliá-los e aprová-los segundo aspectos técnicos e legais vigentes na região.

\section{g) Construção ou reforma da Central de Resíduos}

Deve ser construído um local para receber os resíduos gerados pelo processo dentro das instalações da fábrica. Este local deve conter divisões independentes para, no mínimo vidro, papel, metal, resíduos orgânicos e resíduos perigosos. Deve conter, também, um sistema de calhas para direcionamento de águas pluviais, evitando, assim, inundações durante eventuais chuvas fortes.

\subsection{EtAPA 2 - ConfecÇÃo do PROCEDIMENTO de CONTROLE OPERACIONAL}

Esta etapa é aquela que demandará maior dedicação do comitê, pois nela será desenvolvido o documento de controle operacional. A figura 2 apresenta um fluxo das etapas presentes neste procedimento.

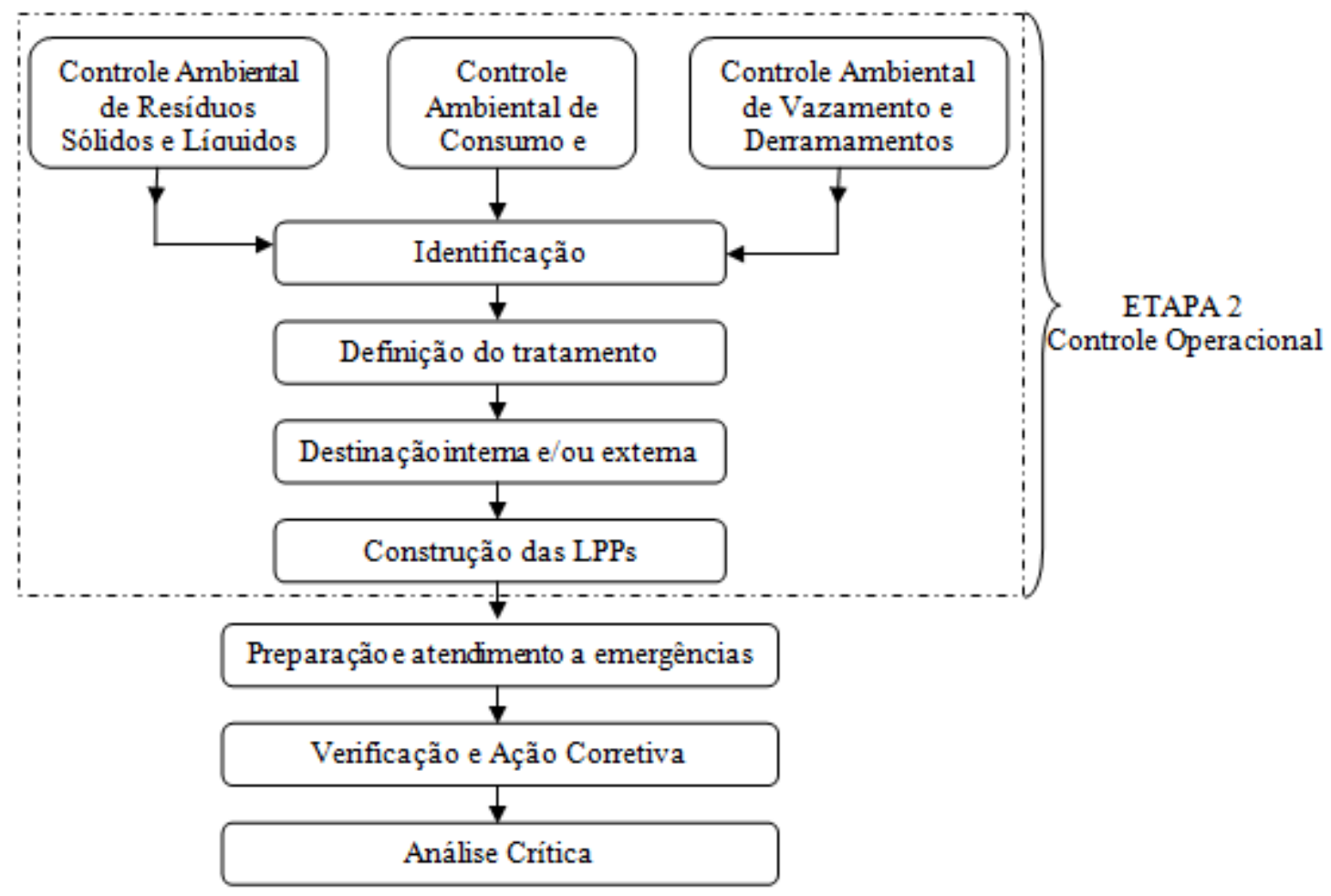

Figura 2. Fluxograma de implantação na fase de Confecção do Procedimento de Controle Operacional

Nesta etapa é importante que se exponha informações de maneira mais detalhada possível. Basicamente, o processo de confecção do procedimento de controle operacional se dará da seguinte forma:

$\checkmark$ Identificação de todas as áreas geradoras de resíduos ou aspecto ambiental envolvido;

$\checkmark$ Definição do tratamento do resíduo ou aspecto;

$\checkmark$ Definição do destino interno (interior da empresa) para o resíduo;

$\checkmark$ Definição do destino externo (fornecedor de serviços ambientais) para o resíduo;

$\checkmark$ Construção das LPPs, se possível, para cada item do Controle Operacional.

Para tanto, é importante que a empresa tenha conhecimento sobre as fontes geradoras de possíveis impactos ambientais, para que possa desenvolver o seu plano de contenção destes. No caso deste artigo, o processo de fundição serve, na maioria das vezes, às indústrias de base. Esse tipo de processo está intimamente relacionado com o processamento de metais, sejam suas matérias-primas naturais (minérios) ou sucatas; por conseguinte, o produto pode ser uma peça pronta para seu uso-fim ou uma 
peça intermediária que necessitará de ajustes posteriores.

De um modo geral, pode-se dizer que o processo de fundição com areia consiste nas seguintes etapas: primeiramente faz-se um molde de isopor ou de madeira; depois esse molde é recoberto por areia misturada a uma resina que a enrijecerá; após o enrijecimento, o molde é retirado e nesta parte "oca" será entornado o metal líquido a alta temperatura. Ao final do processo, a areia finda queimada pelo metal e é descartada ou recuperada para reutilização. A peça bruta segue para as demais etapas do processo, onde será aprimorada.

A areia usada pode ser extraída a seco (quando ela se encontra em montes) ou pode ser retirada por dragagem. Neste último caso, é construída uma lagoa de onde é retirada uma polpa de água com areia do subsolo por uma draga. Pode-se dizer que os principais aspectos ambientais encontrados são a erosão e o assoreamento do solo. Como consequência, tem-se o empobrecimento do solo, destruição vegetativa do perímetro de dragagem, redução da profundidade do leito e comprometimento da qualidade da água. Ademais, nem toda a areia retirada é usada, de modo que uma parte retorna para a lagoa de onde foi retirada ou vai para um local específico para esse recebimento. Toda essa movimentação de terra, junto com o assoreamento, é outro aspecto ambiental relevante.

Em relação ao equipamento utilizado (draga), utiliza-se óleo diesel como combustível e, pelo fato de a polpa da areia ser uma substância bastante abrasiva, ele precisa de constante manutenção. Assim, o risco de vazamento de óleo é constante, podendo poluir a água superficial e o solo. Em alguns casos, ainda há um gerador de eletricidade movido a óleo diesel que serve para alimentar uma bomba centrífuga. Esta suboperação tem como principal aspecto ambiental a geração de ruídos e materiais particulados do funcionamento do gerador e da bomba centrífuga. Na etapa em que a areia passa por um cone classificador, o principal aspecto ambiental é a vibração que afugenta pequenos animais e em ocasiões onde há ventania uma nuvem de areia é levada e depois se deposita na área ao redor.

O beneficiamento é, normalmente, feito em um só lugar da fábrica, destinado à secagem do material que chega úmido da mineração. $\mathrm{Na}$ etapa em que se acomoda a areia, o principal aspecto ambiental é o vazamento de óleos e graxas já que os equipamentos estão sujeitos à abrasividade da areia, podendo sofrer fraturas e, consequentemente, vazamento de óleo lubrificante. Em seguida, a fase de elevador de canecas e o queimador, propriamente dito, é a de impacto ambiental mais relevante. Os aspectos relacionados com essa fase são: geração de ruído, geração de fumos, gases e poeiras, vazamento de óleos e graxas, cujos principais impactos são a poluição sonora, a poluição atmosférica, a intoxicação e a poluição do solo e da água. Os equipamentos correspondentes ao restante do processo possuem, praticamente, as mesmas características no que diz respeito aos impactos ambientais.

Assim, com o objetivo de separar os três grandes grupos de aspectos ambientais com potencial de gerar impactos, o documento 'Controle Operacional' pode ser subdivido em três partes:

a) Plano de Controle Ambiental de Resíduos Sólidos e Líquidos: O objetivo deste é registrar a quantidade e garantir o fiel destino dos resíduos sólidos e líquidos. O plano deve ser feito considerando todos resíduos gerados pela produção e pelas atividades de apoio, como administração e serviço médico.

b) Plano de Controle Ambiental de Consumos e Emissões: O plano de controle ambiental de consumos e emissões deve ser feito considerando os elementos de consumo e emissão, gerados tanto pela atividade produtiva como pelas atividades de apoio, como administração e o serviço médico.

c) Plano de Controle Ambiental de Vazamentos ou Derramamentos: O plano de controle ambiental de vazamentos e derramamentos é feito com base em elementos de vazamentos e derramamentos gerados no processo de produção.

As informações que devem ser relacionados nestes planos de controle são:

1) Número sequencial: identificação do item analisado (código);

2) Descrição:

a. Qual é o tipo de resíduo: sólido ou líquido; ou

b. Qual é o tipo de aspecto ambiental: consumo ou emissão; ou

c. Qual é o tipo de aspecto ambiental: vazamento ou derramamento.

3) Área (quando aplicável): local de geração do citado resíduo; ou local de origem do aspecto;

4) Cuidados (quando aplicável): breves recomendações de segurança no manuseio do material. 
Geralmente, tarefas são mais detalhadas nas LPPs;

5) Destino: Armazenamento ou acondicionamento (resíduos) temporário (interior da empresa);

6) Disposição final / responsável: destino externo do resíduo (quando aplicável) e o responsável pelo envio do material ou pelo controle.

Além disso, é importante estabelecer como será o monitoramento destes planos. Para tanto, algumas informações devem ser adicionadas, tais como:

1) Unidade de medida (quando aplicável): dimensão utilizada para registrar o item (kg, tonelada, peça, m3, etc.);

2) Frequência da verificação: intervalo de tempo que será monitorado o item;

3) Registro: tipo de registro que será usado como evidência da geração ou destinação do resíduo, por exemplo;

4) Responsável: quem registrará os dados.

Paralelamente a isso, a administração da rotina do controle operacional deve ser realizada próximo ao pátio de resíduos, com o objetivo de ter o domínio de todas as ações, o controle da documentação e uma visão clara do inventário físico dos resíduos.

Para finalizar o princípio de 'Implementação e Operação' de um SGA, tem-se a etapa de 'Preparação e atendimento a emergências'. A organização deve estabelecer e manter mecanismos que possam ser acionados a qualquer momento para atender a situações de emergência e eventos não controlados. Isso implica em identificar as possíveis situações emergenciais, definir formas de mitigar os impactos associados, prover os recursos necessários e treinar, periodicamente, uma brigada de emergência (Nicolella et al., 2004).

\section{ESTUDO DE CASO: IMPLANTAÇÃO DA METODOLOGIA PROPOSTA EM UMA FUNDI- ÇÃO}

A empresa cujas instalações serviram como base para a implantação e avaliação deste modelo foi uma Fundição de ferro e aço, localizada no Nordeste do Brasil. As duas principais matérias-primas da empresa são a sucata de metal e a areia. O processo apresenta elevada variação no padrão de qualidade desses dois elementos. No primeiro caso, a baixa oferta de sucata na região não oferece uma seletividade adequada na aquisição, ou seja, a empresa praticamente adquire o que lhe é ofertado. Já no segundo caso, o da areia, poucas áreas de lavra na região oferecem o produto com a especificação requerida, obrigando a empresa a possuir um único fornecedor.

Mesmo assim, em função da natural variação geológica na mesma área de lavra, é comum que se receba areia com especificações distintas entre uma carga de recebimento e outra. Essas características da matéria-prima refletem na qualidade intermediária do produto no decorrer do processo de produção, ao exigir um índice de recuperação interna (recuperação por solda) elevado, o que, por conseguinte, também justifica a forte atuação dos trabalhos voltados para relatórios de não conformidade dentro do escopo procedimental das ações corretivas. Isso não caracteriza um problema ambiental, propriamente dito, mas de qualidade de processo.

Até o momento, por via oficial, não houve nenhuma ocorrência ambiental que a empresa pudesse ser notificada, porém a própria característica do empreendimento lhe põe em risco nesse sentido, pois possui altíssimo potencial para tais ocorrências. Tal condição motiva a empresa a estabelecer padrões de controles ambientais com vista em sistemas de gestão voluntários, cujo caráter é essencialmente preventivo: estabelecer regras para conduta em eventuais ocorrências ou estabelecer regras para conduta de ocorrências ambientais inerentes ao processo e do cotidiano, ou seja, o 'Controle Operacional'. Durante o processo de implementação do controle operacional, observou-se alguns pontos, que serão relatados seguindo o modelo proposto.

\section{I Etapa I - Preparação}

Nesta fase serão enfatizados todos os requisitos necessários para organizar a empresa, para, então, implementar o controle operacional e, consequentemente, o SGA e futuras certificações. 
a) Definição das responsabilidades e autoridades

Sob o ponto de vista administrativo, a empresa possuía, como base sistêmica, a certificação de qualidade ISO 9000. O escopo documental resumia-se no manual da qualidade, nos procedimentos sistêmicos e nas especificações técnicas. Não havia procedimentos de postos de trabalho, pois as informações pertinentes constavam dos procedimentos sistêmicos. Procedimentos de postos de trabalho somente eram elaborados face à necessidade de se realizar alguma operação específica, fruto de algum desvio de especificação ou algo semelhante.

Dentre os elementos de garantia de qualidade mais importantes para empresas com essa característica (fundição), havia um forte e bem estruturado sistema de ações corretivas, amparados por procedimentos sistêmicos, dos quais se demandavam relatórios de não conformidade para problemas técnicos (produtos) e sistêmicos (procedimentos, especificações). A rotina da empresa, até então, não permitia que trabalhos mais voltados para atividades de ações preventivas fossem desenvolvidos, ficando essa área um pouco deficitária nesse sentido.

No tocante ao controle do processo propriamente dito, a rotina consistia apenas em controlar as questões voltadas para as receitas de formulações de misturas de areia com resina (na Moldagem) e ajustes de elementos de ligas nos metais líquidos (Aciaria). Não havia Controle Estatístico de Processo no decorrer do processo de fabricação, nem havia uma avaliação de capabilidade de processo, muito embora houvesse bastante campo para esse tipo de trabalho.

Esta sistemática já existente facilitou a definição de um escopo de responsabilidades e autoridades, bem como a elaboração de uma política ambiental baseada no texto da política de qualidade.

\section{b) Comunicação interna e preparação dos envolvidos:}

Decidiu-se realizar uma campanha educativa com a distribuição de panfletos de tamanho pequeno durante três semanas. A cada entrada de expediente, os funcionários recebiam uma enquete com indagações ou aforismos objetivos a respeito do meio ambiente, como mostra exemplos na figura 3.

$\checkmark$ Na primeira semana os panfletos continham informações que deixavam os colaboradores curiosos em relação ao que se dizia (figura 3.a). (figura 3.b)

$\checkmark$ Na segunda semana apresentaram-se alguns conceitos importantes sobre o meio ambiente

$\checkmark$ Na última semana definiram-se formas de cuidar do meio ambiente (figura 3.c).

(a)

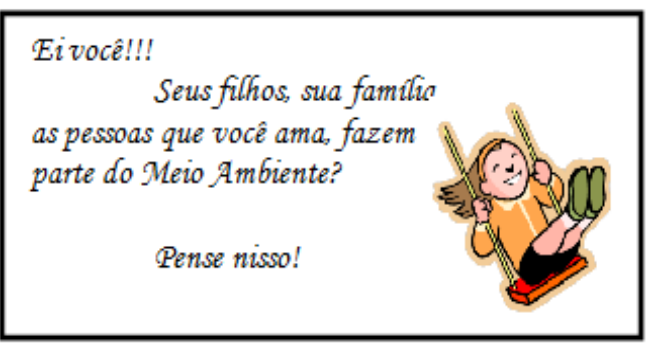

(b)

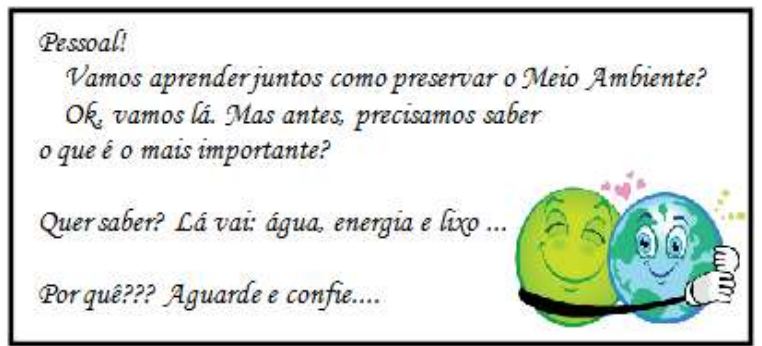

(c)

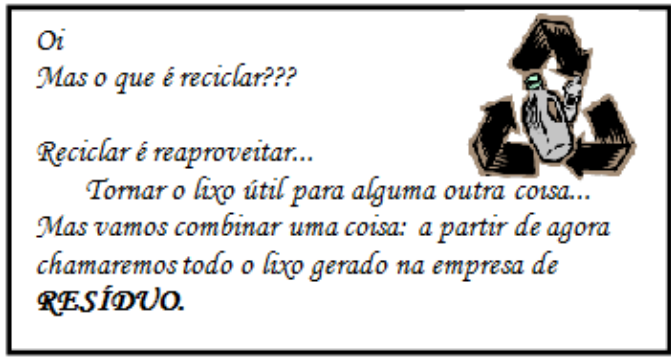

Figura 3. Exemplos da campanha interna 
Observou-se que essa característica da comunicação foi importante no tocante à difusão das ideias pelos próprios trabalhadores para eles mesmos. Na sequência, após essa campanha educativa, utilizou-se o próprio cronograma de reuniões da empresa para difundir as informações necessárias aos envolvidos. Não se observaram resistências por parte de nenhum nível hierárquico da organização.

c) Definição da hierarquia documental:

Para o caso das empresas de Fundição, considera-se um sistema de gestão voluntário, cuja estrutura documental pode ser, à posteriori, utilizada para a implantação da ISO 14001, como forma de organizar o SGA. Neste sentindo, Valls (1995) estabeleceu quatro níveis para uma estrutura típica de hierarquia documental para um sistema voluntário de gestão da qualidade, tendo como guia a ISO 9000, que são: (1) manual da qualidade, (2) procedimentos, (3) instruções de trabalho e (4) registros da qualidade. Essa subdivisão tornou-se parte do senso comum quando se deu a implantação de sistemas de gestão voluntários, estes se assemelhando a ISO 14001. Assim, usando esta hierarquia, os conceitos da TQM e TPM, se adequando à Gestão Ambiental, propõe-se o estabelecimento de uma hierarquia documental em cinco níveis, a figura 4 mostra os níveis hierárquicos da documentação.

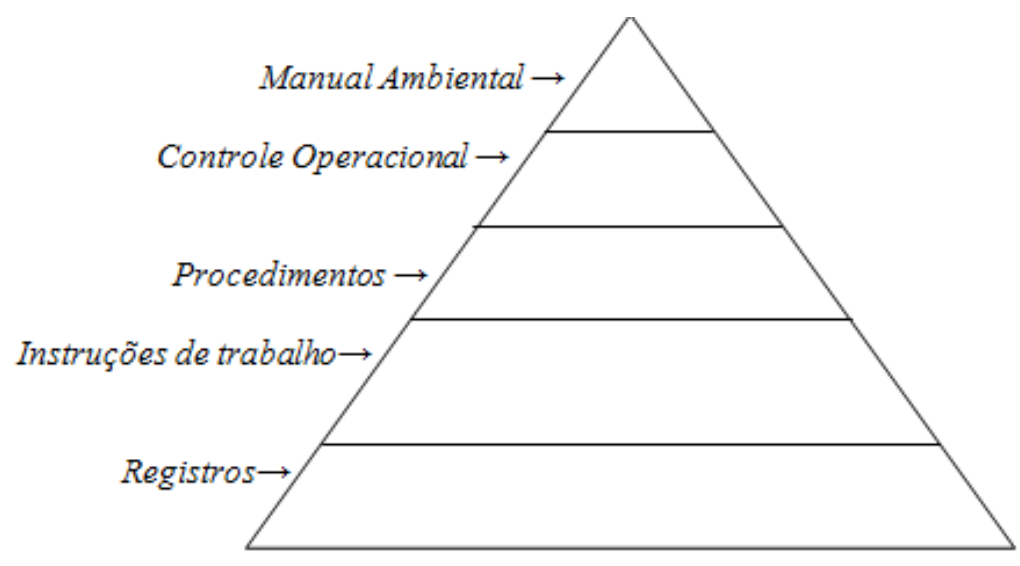

Figura 4. Hierarquia documental

1. Manual Ambiental: Deve conter informações gerais sobre o programa de gestão ambiental adotado pela empresa;

2. Controle Operacional: É o documento base do SGA, deve conter todos os procedimentos, a fim de que sejam atingidas as diretrizes do SGA. Deste poderão derivar as instruções de trabalho. 3. Procedimentos de Gestão: Estabelecem as responsabilidades e as práticas adotadas no SGA ('o que se faz');

4. Instruções de Trabalho: estabelecem as rotinas para os controles operacionais e monitoramentos, garantindo os níveis de desempenho ambiental estabelecidos ('como se faz'). Composto por:

a. Especificações: Contém itens técnicos em relação às etapas do processo fabril.

b. Lições Ponto a Ponto (LPP): Localizadas nos postos de trabalho, devem conter informações específicas sobre o desenvolvimento de determinada atividade.

5. Registros: evidenciam a implementação e manutenção do SGA e fornecem informações para demonstrar seu desempenho e planejar novos ciclos de melhoria contínua, assim como estabelecem os requisitos mínimos aceitáveis de desempenho.

É importante ressaltar que a empresa já adotava modelo similar para o atendimento da gestão da qualidade. Assim, para facilitar o processo, é importante não gerar grandes mudanças no que já esta sendo feito, mas, sim, adequar-se à nova realidade.

d) Cadastro de fornecedores de serviços ambientais:

O principal tipo de fornecedor de serviço ambiental foi do tipo receptor de resíduos industriais para reciclagem ou aterramento sanitário industrial. Os critérios utilizados para a seleção desses fornecedores foram os mesmos critérios estabelecidos pelos procedimentos da ISO 9000, utilizado pela empresa; além desses critérios, que em sua base são mais comerciais e fiscais, houve a necessidade 
da solicitação de licenças ambientais de funcionamento, além da ocorrência de visitas técnicas de membros da empresa nas instalações dos candidatos a fornecedores, para se avaliar alguns aspectos técnicos envolvidos.

e) Construção ou reforma da central de resíduos:

Inexistiam coletas seletivas, apesar de haver uma área destinada para esse fim. Essa área era dividida em baias conforme a característica de cada tipo de resíduo, mas, em virtude da falta de gerenciamento específico, os produtos estavam quase sempre misturados e fora do perímetro estabelecido para seu armazenamento. Os destinos desses resíduos não eram controlados pelos setores afins. Além disso, a Central de Resíduos, por não ter sido gerenciada para esse fim, necessitou de uma reforma para se adequar ás características de sinalização que se necessitava.

Um colaborador da produção foi treinado para gerenciar a Central no horário administrativo e determinou-se que o seu funcionamento somente se daria nesse horário, embora houvesse pontos de coletas móveis no decorrer de todo o processo produtivo, para coletar os resíduos e, na sequencia, conduzi-los à Central.

\subsection{Etapa 2 - Confecção do Controle Operacional:}

$\mathrm{Na}$ empresa não havia nada realiado no que tange o Controle Operacional, nem mesmo o que pudesse ser aproveitado para a elaboração deste documento. Desta maneira, o que foi proposto e desenvolvido sugere um padrão que seja aplicável a qualquer Sistema de Beneficiamento de Areia de fundições que produzam ferro e aço.

Para a confecção do documento do Controle Operacional é necessário que se tenha, a priori, conhecimentos sobre processo de produção propriamente dito e, por conseguinte, conhecimento técnico acerca dos itens relacionados. Além disso, deve-se considerar o arcabouço de resíduos gerados e os aspectos ambientais vigentes na ocasião da elaboração do documento. É importantíssimo que as informações tracem um status quo do processo com toda fidelidade, para que posteriores monitoramentos ambientais sejam exatos. Como base para a avaliação, devem ser listados resíduos sólidos, resíduos líquidos, consumos, emissões, vazamento e/ou derramamentos.

O monitoramento ambiental será efetuado por intermédio dos dados obtidos de registros dos itens do Controle Operacional. Assim, a tabela 1 apresenta uma estrutura de controle operacional com os itens mínimos necessários, com base na descrição apresentada no modelo proposto. Ressalta-se que existem outros itens a serem considerados, mas, devido à extensão, não puderam ser apresentados aqui.

Tabela 1 - Estrutura do controle operacional

\begin{tabular}{|c|c|c|c|c|c|}
\hline $\begin{array}{c}N^{\circ} \\
\text { seq. }\end{array}$ & Descrição & Área & Cuidados & Destino & Disposição final \\
\hline $1 \mathrm{RS}$ & $\begin{array}{l}\text { Areia bruta } \\
\text { (finos e grossos) }\end{array}$ & $\begin{array}{l}\text { Sist. de Benef. } \\
\text { de Areia } \\
\text { Interno }\end{array}$ & $\begin{array}{l}\text { Acondicionar em caçambas } \\
\text { adequadas }\end{array}$ & $\begin{array}{l}\text { Acomodar } \\
\text { no pátio de } \\
\text { Areia }\end{array}$ & $\begin{array}{l}\text { Destino: Uso } \\
\text { na construção } \\
\text { civil }\end{array}$ \\
\hline 2 RS & $\begin{array}{l}\text { Areia com } \\
\text { resina (crua) }\end{array}$ & Moldagem & $\begin{array}{l}\text { Acondicionar em caçambas } \\
\text { adequadas }\end{array}$ & $\begin{array}{l}\text { Acomodar } \\
\text { no pátio de } \\
\text { Resíduos }\end{array}$ & $\begin{array}{l}\text { Destino: } \\
\text { Aterro } \\
\text { Industrial }\end{array}$ \\
\hline $3 \mathbf{R S}$ & $\begin{array}{l}\text { Areia com } \\
\text { resina } \\
\text { (queimada) }\end{array}$ & Moldagem & $\begin{array}{l}\text { Fazer movimentação com } \\
\text { transporte mecânico aberto ou } \\
\text { fechado }\end{array}$ & $\begin{array}{l}\text { Fazer } \\
\text { silagem }\end{array}$ & $\begin{array}{l}\text { Destino: } \\
\text { Recuperar ou } \\
\text { aterro } \\
\text { industrial }\end{array}$ \\
\hline $\begin{array}{l}1 \\
\text { RL }\end{array}$ & $\begin{array}{l}\text { Efluentes da } \\
\text { lavagem da } \\
\text { areia }\end{array}$ & $\begin{array}{l}\text { Sist. de Benef. } \\
\text { de Areia } \\
\text { externo }\end{array}$ & Usar EPI's adequados & \begin{tabular}{|l|} 
Levar p/ \\
lagoa de \\
estabilizaçã \\
o
\end{tabular} & $\begin{array}{l}\text { Destino: } \\
\text { Reuso }\end{array}$ \\
\hline
\end{tabular}

*RS para resíduos sólidos; RL para resíduos líquidos; CO de consumo; EM de emissão; VD para vazamentos. 
Tabela 1 - Continuação...

\begin{tabular}{|c|c|c|c|c|c|}
\hline $\begin{array}{c}N^{\circ} \\
\text { seq. }\end{array}$ & Descriçãao & Área & Cuidados & Destino & Disposição final \\
\hline $\begin{array}{l}2 \\
\mathrm{RL}\end{array}$ & \begin{tabular}{|l|} 
Efluentes \\
líquidos de \\
limpeza do piso \\
interno da \\
Administração
\end{tabular} & $\begin{array}{l}\text { Administraçã } \\
\text { o }\end{array}$ & $\begin{array}{l}\text { Utilizar aspirador de água, } \\
\text { pano de chão/balde ou } \\
\text { máquina de lavar piso para } \\
\text { remover toda a água. }\end{array}$ & $\begin{array}{l}\text { Descartar } \\
\text { no ralo de } \\
\text { esgoto } \\
\text { sanitário }\end{array}$ & $\begin{array}{l}\text { Destino: Rede } \\
\text { de esgotos }\end{array}$ \\
\hline $\begin{array}{l}1 \\
\mathrm{CO}\end{array}$ & \begin{tabular}{|l} 
Consumo de \\
água industrial
\end{tabular} & $\begin{array}{l}\text { Fábrica / } \\
\text { Utilidades }\end{array}$ & $\begin{array}{l}\text { Identificar os consumos da } \\
\text { água em todas as etapas do } \\
\text { processo que a exijam. Verificar } \\
\text { sistematicamente a ocorrência } \\
\text { de vazamentos (em caso } \\
\text { positivo corrigir } \\
\text { imediatamente) }\end{array}$ & $\begin{array}{l}\text { Não se } \\
\text { aplica }\end{array}$ & $\begin{array}{l}\text { Responsáveis: } \\
\text { Operadores }\end{array}$ \\
\hline $\begin{array}{l}2 \\
\mathrm{CO}\end{array}$ & $\begin{array}{l}\text { Consumo de } \\
\text { água potável }\end{array}$ & Geral & $\begin{array}{l}\text { Acompanhar o } \\
\text { qualitativamente consumo } \\
\text { quando da utilização de } \\
\text { chuveiros, pias, bacias } \\
\text { sanitárias, bebedouros, } \\
\text { mangueiras de incêndios, } \\
\text { limpeza de banheiros e } \\
\text { vestiários, jardinagem e } \\
\text { preparação de alimentos. } \\
\text { Verificar sistematicamente a } \\
\text { ocorrência de vazamentos }\end{array}$ & $\begin{array}{l}\text { Não se } \\
\text { aplica }\end{array}$ & $\begin{array}{l}\text { Responsáveis: } \\
\text { Todos os } \\
\text { envolvidos } \\
\text { com as } \\
\text { atividades que } \\
\text { consomem } \\
\text { água. }\end{array}$ \\
\hline $\begin{array}{l}3 \\
\text { co }\end{array}$ & $\begin{array}{l}\text { Consumo de gás } \\
\text { liquefeito de } \\
\text { petróleo (GLP) }\end{array}$ & $\begin{array}{l}\text { Fábrica / } \\
\text { Utilidades }\end{array}$ & $\begin{array}{l}\text { Desligar empilhadeira quando } \\
\text { não estiver usando; Certificar } \\
\text { que não há vazamentos quando } \\
\text { da substituição do botijão e/ou } \\
\text { manuseios; Caso o } \\
\text { equipamento venha apresentar } \\
\text { alguma irregularidade, solicitar } \\
\text { manutenção. }\end{array}$ & $\begin{array}{l}\text { Não se } \\
\text { aplica }\end{array}$ & $\begin{array}{l}\text { Responsáveis: } \\
\text { Operadores e } \\
\text { Manutenção }\end{array}$ \\
\hline $\begin{array}{l}1 \\
\text { EM }\end{array}$ & \begin{tabular}{|l} 
Emissão de \\
particulados \\
gerados no \\
transporte de \\
areia
\end{tabular} & $\begin{array}{l}\text { Sist. de Benef. } \\
\text { de Areia } \\
\text { Interno / } \\
\text { Moldagem }\end{array}$ & $\begin{array}{l}\text { Executar manutenção e } \\
\text { limpeza programada nos } \\
\text { equipamentos }\end{array}$ & $\begin{array}{l}\text { Não se } \\
\text { aplica }\end{array}$ & $\begin{array}{l}\text { Responsáveis: } \\
\text { Manutenção }\end{array}$ \\
\hline $\begin{array}{l}1 \\
\text { VD }\end{array}$ & $\begin{array}{l}\text { Produtos } \\
\text { químicos em } \\
\text { geral (líquidos } \\
\text { não viscosos) }\end{array}$ & $\begin{array}{l}\text { Manutenção } \\
\text { / Fábrica / } \\
\text { Restaurante / } \\
\text { Logística / } \\
\text { Utilidades }\end{array}$ & $\begin{array}{l}\text { Utilizar EPIS. Conter o } \\
\text { vazamento ou derramamento } \\
\text { com barreiras de cordões } \\
\text { absorvedores ou turfa. Fechar } \\
\text { válvula de saída do produto } \\
\text { quando aplicável. Recolher } \\
\text { com manta absorvedora, turfa } \\
\text { ou toalha industrial. Torcer as } \\
\text { mantas, toalhas e cordões } \\
\text { descarregando o óleo em } \\
\text { recipientes para atendimento às } \\
\text { emergências ou recolher a turfa } \\
\text { com rodo e pá e acondicionar } \\
\text { em recipientes para } \\
\text { atendimento á emergências. } \\
\text { Identificar com etiqueta. } \\
\text { Encaminhar toalhas, óleo, } \\
\text { mantas e cordões conforme } \\
\text { Plano de Controle Ambiental } \\
\text { para Resíduos. }\end{array}$ & $\begin{array}{l}\text { Não se } \\
\text { aplica }\end{array}$ & $\begin{array}{l}\text { Responsáveis: } \\
\text { Manutenção/ } \\
\text { Operadores/ } \\
\text { Empilhadores }\end{array}$ \\
\hline
\end{tabular}

*RS para resíduos sólidos; RL para resíduos líquidos; CO de consumo; EM de emissão; VD para vazamentos. 
A tabela 2 apresenta as informações pertinentes ao gerenciamento do monitoramento e verificação dos planos de controle.

Tabela 2 - Monitoramento e verificação no controle operacional

\begin{tabular}{|c|c|c|c|c|c|}
\hline$N^{\circ}$ seq. & Descrição & Unidade & Registro & $\begin{array}{l}\text { Freq. de } \\
\text { verificação }\end{array}$ & Responsável \\
\hline $1 \mathrm{RS}$ & Areia bruta (finos e grossos) & Tonelada & $\begin{array}{l}\text { Formulário próprio / } \\
\text { Nota fiscal }\end{array}$ & Diária & Operador \\
\hline 2 RS & Areia com resina (crua) & Tonelada & $\begin{array}{l}\text { Formulário próprio / } \\
\text { Nota fiscal }\end{array}$ & Diária & Operador \\
\hline 3 RS & Areia com resina (queimada) & Tonelada & $\begin{array}{l}\text { Formulário próprio / } \\
\text { Nota fiscal }\end{array}$ & Diária & Operador \\
\hline $1 \mathrm{RL}$ & Efluentes da lavagem da areia & $\mathrm{m}^{3}$ & Formulário próprio & Diária & Operador \\
\hline $2 \mathrm{RL}$ & $\begin{array}{l}\text { Efluentes líquidos de limpeza } \\
\text { do piso interno da } \\
\text { Administração }\end{array}$ & $\mathrm{m}^{3}$ & Formulário próprio & Diária & $\begin{array}{l}\text { Empresa de limpeza } \\
\text { e conservação }\end{array}$ \\
\hline $1 \mathrm{CO}$ & Consumo de água industrial & $\mathrm{m}^{3}$ & $\begin{array}{l}\text { Formulário próprio / } \\
\text { conta de água }\end{array}$ & Diária & Operadores \\
\hline $2 \mathrm{CO}$ & Consumo de água potável & $\mathrm{m}^{3}$ & $\begin{array}{l}\text { Formulário próprio / } \\
\text { conta de água }\end{array}$ & Diária & $\begin{array}{l}\text { Todos os envolvidos } \\
\text { com as atividades } \\
\text { que consomem } \\
\text { água. }\end{array}$ \\
\hline $3 \mathrm{CO}$ & $\begin{array}{l}\text { Consumo de gás liquefeito de } \\
\text { petróleo (GLP) }\end{array}$ & $\mathrm{kg}$ ou L & $\begin{array}{l}\text { Formulário próprio / } \\
\text { nota fiscal }\end{array}$ & Diária & $\begin{array}{l}\text { Operadores e } \\
\text { Manutenção }\end{array}$ \\
\hline $1 \mathrm{EM}$ & $\begin{array}{l}\text { Emissão de particulados } \\
\text { gerados no transporte de } \\
\text { areia }\end{array}$ & $\mathrm{kg}$ & PPRA & Semestral & $\begin{array}{l}\text { Segurança do } \\
\text { Trabalho }\end{array}$ \\
\hline $1 \mathrm{VD}$ & $\begin{array}{l}\text { Produtos químicos em geral } \\
\text { (líquidos não viscosos) }\end{array}$ & $\begin{array}{l}\text { Não se } \\
\text { aplica }\end{array}$ & Livro de Ocorrência & $\begin{array}{l}\text { Quando da } \\
\text { ocorrência }\end{array}$ & $\begin{array}{l}\text { Manutenção } \\
\text { /Operadores / } \\
\text { Empilhadores }\end{array}$ \\
\hline
\end{tabular}

\section{RESULTADOS}

Para que o Controle Operacional fosse totalmente implementado, foi necessário, aproximadamente, um ano. A participação dos colaboradores da produção foi importante para a sua operacionalização, principalmente, na identificação dos impactos ambientais passíveis de controle. Isso os motivou a manter o sistema em funcionamento rotineiro após o período de implantação. A motivação que os colaboradores, principalmente os que faziam parte da produção, a sistemática normativa pré-estabelecida em função da existência de uma ISO 9000 e a pré-existência de um pátio de resíduos (mesmo que, a princípio, não adequado) foram os principais pontos de apoio à implantação do controle operacional. Assim, após um ano de implantação do Controle Operacional, os resultados alcançados podem ser listados e estes são:

1. A empresa passou a ter conhecimento sobre a quantidade exata dos resíduos sólidos gerados por mês;

2. A empresa passou a ter controle da destinação final dos resíduos

o A geração de resíduos, bem como os destinos finais destes, passou a ser rastreado por notas fiscais; 
3. A empresa passou a ter mais eficiência produtiva operacional em virtude da redução dos desperdícios;

${ }^{\circ}$ Houve diminuição de cerca de $10 \%$ nos transportes de caminhões com cargas de areia descartada, em função da padronização da carga;

- Aareia (finos e grossos, sem resina queimada) descartada passou a ser comercializada gerando receitas para a empresa;

- Alguns resíduos sólidos, tais como madeira, passaram a ser comercializados gerando receita para a empresa;

- Os resíduos sólidos metálicos passaram a ser redirecionados para retorno aos fornos de fusão; 4. A empresa passou a possuir uma única área, organizada e sistematizada, para servir de ponto administrativo para gestão ambiental (pátio de resíduos);

- O pátio de resíduos existente foi reformado e encontra-se em bom estado de conservação;

5. A empresa passou a ter maior responsabilidade ambiental e social:

- Todos os colaboradores puderam perceber que a empresa possui uma gestão ambiental;

- Todos os colaboradores passaram a entender a necessidade de distinção entre políticas de qualidade, políticas ambientais ou outras políticas afins;

- Os colaboradores passaram a estar mais motivados para trabalhar, no sentido de atendere a novos projetos dessa natureza.

- A empresa passou a estar em conformidade com as leis ambientais vigentes;

6. O Controle Operacional implantando prepara a empresa para a futura certificação à norma ISO 14.001;

Contudo, verificam-se algumas dificuldades durante a implantação do Controle Operacional. As principais estão relacionadas à dificuldade em cumprir os prazos estabelecidos nas reuniões de implantação; da dificuldade em se reunir os integrantes, em função das responsabilidades rotineiras de cada um; ao aumento do número de controles necessários, ao aumento da burocracia interna e, consequentemente, a maior possibilidade de erros administrativos. Além disso, estas dificuldades levaram a um pequeno aumento do custo com mão de obra para a empresa.

\section{CONSIDERAÇÕES FINAIS}

As areias utilizadas em processos de fundição são alvo de estudos ambientais devido ao impacto que causam os seus processos de beneficiamento e de extração. O desenvolvimento da legislação específica, relativa ao assunto, indica que irão surgir, em um futuro próximo, mais exigências legais ou de mercado, relativas aos impactos que essa atividade causa. Dentre as atividades de extração e beneficiamento, a atividade de extração é aquela que gera mais impactos ambientais negativos. Como consequência, tem-se o esgotamento de recursos naturais da região e o comprometimento da flora e fauna.

Além do atendimento às exigências legais por parte da empresa, a base da gestão ambiental é o controle dos resíduos gerados pelo seu processo industrial ou administrativo e trabalhar no sentido de evoluir no tocante à redução da geração desses resíduos. Também é parte do escopo da gestão agir nas emergências ambientais. Neste sentido, o principal documento para a gestão ambiental em uma empresa é o Controle Operacional, pois dele surgirão todos os procedimentos pertinentes.

A decisão de implantação de uma gestão por parte da empresa não está, necessariamente, vinculada a alguma exigência de mercado. Basta que faça parte do viés de valores da alta administração da organização em questão. Em princípio, também não é necessário vincular a gestão ambiental a uma norma oficial, como é o caso da série ISO 14.001. O mais importante é criar uma sistemática de controle e fazer funcioná-la.

Assim, este trabalho apresentou um modelo de implementação de um controle operacional para servir como base para a implantação de um sistema de gestão ambiental em indústrias de fundição. A estrutura do Controle Operacional proposto pode ser utilizada na rotina do dia a dia para a gestão ambiental. Um estudo de caso foi apresentado em uma indústria de fundição com sistemas de beneficiamento de areia. Observa-se que as vantagens da implantação do sistema superam as desvantagens, 
sendo estas, de maneira geral, oriundas do aumento da 'burocracia' ou do 'controle' exigido. Porém, nenhuma empresa consegue alavancar suas atividades e sua responsabilidade social sem aumentar destes controles.

Como sugestão de avanços nesta pesquisa deixa-se a necessidade de enfatizar as demais fases necessárias para a completa implementação do SGA na empresa, bem como fazer uso desta para conseguir a certificação da ISO 14001.

\section{REFERÊNCIAS}

ASSOCIAÇÃO BRASILEIRA DE NORMAS TÉCNICAS (ABNT). Normas NBR ISO Série ISO 14000. Rio de Janeiro, 2004.

ANGELL, L.C.; KLASSEN, R.D. Integrating environmental issues into the mainstream: an agenda for research in operations management. Journal of Operations Management, v. 48, n 5, p. 575-598, 1999.

ANTON, W. R. Q.; DELTAS, G.; KHANNA, M. Incentives for environmental self-regulation and implications for environmental performance, Journal of Environmental Economics and Management, v. 48, p. 632$654,2004$.

AVILA, G. J.; PAIVA, E. L. Processos operacionais e resultados de empresas brasileiras após a certificação ambiental ISO 14001. Gest. Prod., v. 13, n. 3, p. 475-487, 2006.

BABAKRI, K. A.; BENNETT, R. A.; FRANCHETTI, M. Critical factors for implementing ISO 14001 standard in United States industrial companies. Journal of Cleaner Production, v. 11, p. 749-752, 2003.

BANSAL, P.; BOGNER, W. C. Deciding on ISO 14001: Economics institutions and context. Long Range Planning, v. 35, p. 269-290, 2002.

BELINELLI, M.; PILATTI, L. A.; FRASSON, A. C. A Manutenção Produtiva Total (TPM) como ferramenta para aumento de disponibilidade de máquina: estudo de caso em uma indústria do ramo Siderúrgico. In: XVI SIMPÓSIO DE ENGENHARIA DE PRODUÇÃO - SIMPEP, 2009. Bauru.

BISPO, C. A. F.; CAZARINI, E. W. Avaliação qualitativa paraconsistente do processo de implantação de um Sistema de Gestão Ambiental. Gest. Prod., v. 13, n. 1, p. 117-127, 2006.

BORELLA, I. L.; NAIME, R. TRANSFORMAR A GESTÃO AMBIENTAL INTEGRADA EM VANTAGEM COMPETITIVA. Rev. Elet. em Gestão, Educação e Tecnologia Ambiental, v. 6, n. 6, p. 1025 - 1042, 2012.

BRASIL. Constituição da República Federativa do Brasil. São Paulo: Saraiva, 2005.

BRASIL. Tribunal de Contas da União. Cartilha de licenciamento ambiental / Tribunal de Contas da União; com colaboração do Instituto Brasileiro do Meio Ambiente e dos Recursos Naturais Renováveis. -- 2.ed. -Brasília : TCU, 4ª Secretaria de Controle Externo, 2007.

BRENDLER, E.; BRANDLI, L. L. Integração do sistema de gestão ambiental no sistema de gestão de qualidade em uma indústria de confecções. Gest. Prod., v. 18, n. 1, p. 27-40, 2011.

CASTKA, P.; PRAJOGO, D. The effect of pressure from secondary stakeholders on the internalization of ISO 14001. Journal of Cleaner Production, v. 47, p. 245-252, 2013.

CONSELHO NACIONAL DO MEIO AMBIENTE (CONAMA). Resolução n. 01 de 23 de janeiro de 1986. Diário Oficial da República Federativa do Brasil. Poder Executivo, Brasília, DF, 17 de fev. de 1986. 
DELMAS, M.; TOFFEL, M. W. Organizational responses to environmental demands: opening the black box. Strategic Management Journal, v. 29, p. 1027-1055, 2008.

DIAS, G. F. Educação Ambiental: princípios e práticas. 9ª ed. São Paulo: Gaia, 2004.

Earnhart, D. Effect of Systems to Manage Environmental Aspects on Environmental Performance. Sustainability, v. 5, p. 2557-2588, 2013.

GASBARRO, F.; RIZZI, F.; FREY, M. The mutual influence of Environmental Management Systems and the EU ETS: Findings for the Italian pulp and paper industry. European Management Journal, v. 31, p. 16- 26, 2013.

GAVRONSKI, I.; FERRER, G.; PAIVA, E. L. ISO 14001 certification in Brazil: motivations and benefits. Journal of Cleaner Production, v. 16, p. 87- 94, 2008.

GAVRONSKI, I.; PAIVA, E. L.; TEIXEIRA, R.; ANDRADE, M. C. F. ISO 14001 certified plants in Brazil e taxonomy and practices. Journal of Cleaner Production, v. 39, p. 32-41, 2013.

INOUE, E.; ARIMURA, T. H.; NAKANO, M. A new insight into environmental innovation: Does the maturity of environmental management systems matter? Ecological Economics, v. 94, p. 156-163, 2013.

INTERNATIONAL ORGANIZATION FOR STANDARDISATION (ISO). The ISO Survey - 2004. ISBN 92-67-10410-1.

JOHNSTONE, N.; LABONNE, J. Why do manufacturing facilities introduce environmental management systems? Improving and/or signaling performance. Ecological Economics, v. 68, p. 719-730, 2009.

JONES, C. Exploring new ways of assessing the effect of regulation on environmental management. Journal of Cleaner Production, v. 18, p. 1229-1250, 2010.

LO, C. K.Y.; YEUNG, A. C. L.; CHENG, T.C.E. The impact of environmental management systems on financial performance in fashion and textiles industries. Int. J. Production Economics, v. 135, p. 561-567, 2012.

LUZ, S. O. de C.; SELLITTO, M. A.; GOMES, L. P. Medição de desempenho ambiental baseada em método multicriterial de apoio à decisão:estudo de caso na indústria automotiva. Gest. Prod., v. 13, n 3, p. 557-570, 2006.

MAGGARD, B. N. TPM Maintenance Operations that Work. Cambridge,MA, Productivity Press: 1992.

MELNYK, S. A.; SROUFE, R. P.; CALANTONE, R. Assessing the impact of environmental management systems on corporate and environmental performance. Journal of Operations Management, v. 21, p. 329-351, 2003.

NICOLELLA, G.; MARQUES, J. F.; SKORUPA, L. A. Sistema de gestão ambiental: aspectos teóricos e análise de um conjunto de empresas da região de Campinas, SP.- Jaguariúna: Embrapa Meio Ambiente, 2004.

NISHITANI, K. An empirical study of the initial adoption of ISO 14001 in Japanese manufacturing firms. Ecological Economics, v. 68, p. 669-679, 2009.

NISHITANI, K.; KANEKO, S.; FUJII, H.; KOMATSU, S. Are firms' voluntary environmental management activities beneficial for the environment and business? An empirical study focusing on Japanese manufacturing firms. Journal of Environmental Management, v. 105, p. 121-130, 2012. 
NOGUEIRA, M. A. F. DE S.; GARCIA, M. DA S. Gestão dos resíduos do setor industrial sucroenergético: estudo de caso de uma usina no município de Rio Brilhante, Mato Grosso do Sul. Revista Eletronica em Gestão, Educação e Tecnologia Ambiental - REGET, v. 17, n. 17, p. 3275 - 3283, 2013.

OLIVEIRA, O. J. de; PINHEIRO, C. R. M. S. Implantação de sistemas de gestão ambiental ISO 14001: uma contribuição da área de gestão de pessoas. Gest. Prod., v. 17, n. 1, p. 51-61, 2010.

PAOLI, D.; MORAES, L. A. F. de. Apoio multicritério à decisão como subsídio à gestão ambiental: o caso da Aggreko Brasil. Gest. Prod., v. 18, n. 2, p. 379-390, 2011.

POMBO, F. R.; MAGRINI, A. Panorama de aplicação da norma ISO 14001 no Brasil. Gest. Prod., v. 15, n. 1, p. 1-10, 2008.

PUN, K-F. Development of an integrated total quality management and performance measurement system for self-assessment: A method. Total Quality Management, v. 13, n. 6, p. 759- 777, 2002.

SAVELY, S. M.; CARSON, A. I.; DELCLOS, G. L. An environmental management system implementation model for U.S. colleges and universities. Journal of Cleaner Production, v. 15, p. 660-670, 2007.

SEIFFERT, M. E. B. Environmental impact evaluation using a cooperative model for implementing EMS (ISO 14001) in small and medium-sized enterprises. Journal of Cleaner Production, v. 16, p. 1447-1461, 2008.

SELLITTO, M. A., BORCHARDT, M. \& PEREIRA, G. M. Modelagem para avaliação de desempenho ambiental em operações de manufatura. Gest. Prod., v. 17, n 1, p. 95-109, 2010.

STEVENS, P. A.; BATTY, W. J.; LONGHURST, P. J.; DREW, G. H. A critical review of classification of organisations in relation to the voluntary implementation of environmental management systems. Journal of Environmental Management, v. 113, p. 206-212, 2012.

THOUMY, M.; VACHON, S. Environmental projects and financial performance: Exploring the impact of project characteristics. Int. J. Production Economics, v. 140, p. 28-34, 2012.

TRIERWEILlER, A. C.; PEIXE, B. C. S.; TEZZA, R., BORNIA, A. C.; ANDRADE, D. F. de; CAMPOS, L. M. de S. Environmental management performance for Brazilian industrials: measuring with the item response theory. Work, v. 41, p. 2179-2186, 2012.

VALLE, C. E. do. Qualidade ambiental: ISO 14000. Senac:, São Paulo, 2002.

VALLS, V. M. O gerenciamento dos documentos do sistema de qualidade. Ciência da informação, v. 25, n. 2, 1995.

WIENGARTEN, F.; PAGELL, M. The importance of quality management for the success of environmental management initiatives. Int. J.ProductionEconomics, v. 140, p. 407-415, 2012.

WU, J. Environmental compliance: The good, the bad, and the super green. Journal of Environmental Management, v. 90, p. 3363-3381, 2009.

ZHANG, W.; WANG, W.; WANG, S. Environmental performance evaluation of implementing EMS (ISO 14001) in the coating industry: case study of a Shanghai coating firm. Journal of Cleaner Production, v. 64, p. 205-217, 2014.

ZHU, Q.; CORDEIRO, J.; SARKIS, J. Institutional pressures, dynamic capabilities and environmental management systems: Investigating the ISO 9000 e Environmental management system implementation linkage. Journal of Environmental Management, v. 114, p. 232-242, 2013. 